\title{
UN NOMBRE PROPIO EN LA LITERATURA \\ Y SOCIEDAD MEDIEVAL Y DEL SIGLO XVI: \\ TRISTÁN
}

\author{
María Coduras Bruna \\ Universidad de Zaragoza \\ mcoduras@unizar.es
}

\section{Resumen}

La tristeza va unida a Tristán desde su nacimiento, y así queda inserta en su nombre. Nos proponemos analizar la presencia de este sentimiento y su opuesto en el carácter del héroe a lo largo de diversas obras artúricas y caballerescas, fundamentalmente el Tristán de Leonís (I5OI). También se estudiará la presencia del antropónimo Tristán en la sociedad medieval y áurea, así como su tratamiento en el teatro áureo donde se empleaba para nombrar a criados y rufianes.

\section{Palabras clave}

Tristán, tristeza, antropónimo.

\begin{abstract}
The sadness is joined to Tristan from his birth, and this way it remains inserted in his name. We propose to analyze the presence of this feeling and his opposite in hero's behavior along different Arthurian romances, fundamentally the Tristán de Leonis (I5OI). We will also study the presence of the name Tristan in the medieval and Spanish Golden Age, as well as its treatment in the Spanish Golden Age theatre where it was used to name servants and villains.
\end{abstract}

\section{Keywords}

Tristan, sadness, proper name. 
Triste te he traído al mundo, triste es la primera fiesta que puedo hacerte, por ti siento tristeza de morir. Y como has llegado al mundo en medio de la tristeza, tu nombre será Tristán.

Blancaflor en Tristán e Iseo

El nombre Tristán va indisociablemente unido a la tristeza, la misma a la que hacía referencia su madre Blancaflor en la cita precedente. Nacido en circunstancias pesarosas, pues su madre fallece al nacer y su padre había muerto previamente, dicho sentimiento marcará irremediablemente la trayectoria del héroe.

En este trabajo ofreceremos un panorama de la influencia de este personaje en la narrativa medieval peninsular hasta llegar al Tristán de Leonis, y nos centraremos especialmente en el significado inherente a su nombre y su funcionalidad argumental. Del mismo modo, brindaremos una muestra de su repercusión en la sociedad medieval, en la que este antropónimo ha perdido, en gran medida, su carga semántica para pasar a designar a numerosas personas de carne y hueso. Un camino que termina con la degradación del nombre y el personaje en la comedia áurea.

\section{EL ORIGEN DEL NOMBRE Y LA TRISTEZA}

El antropónimo Tristán parece proceder del picto Drust/Drest y su derivado Drostan, nombre que figura en las listas de los reyes pictos que reinaron entre los siglos viII y IX, y significa 'el tumultuoso, el bullicioso' (Plet-Nicolas, 2007, p. 72). Sin embargo, no es este el sentido que tuvo su nombre para los lectores y autores del Tristan en prose y sus derivados, como fuera el Tristán de Leonís (I5OI) peninsular, al que prestaremos cierta atención, sino aquel asociado a la tristeza.

Como afirmábamos, Tristán está conectado al pesar, del mismo modo que otros personajes posteriores de la producción caballeresca peninsular construidos indudablemente sobre el artúrico responden a unas mismas circunstancias motivadoras. Así ocurre con el Tristarán del Lisuarte de Grecia (1526) de Juan Díaz, hijo de Sabina y Rolando y señor de los montes Bruceos, bautizado así en una escena paralela a la de Blancaflor, aunque sin muerte materna, por la ausencia de su padre ("pues yo te parí con tan grande tristeza, quiero que ayas el nombre 
conforme a tu nascimiento, que en señal que fui triste te llamen Tristarán”, Díaz, I526, cap. 3I, fol. $\left.45^{v}\right)^{\mathrm{I}}$.

No cabe duda de que todos estos personajes están conectados a la madre y a las circunstancias de su nacimiento, remitiendo en origen al Tristán artúrico que los motiva ${ }^{2}$. Pero, dejando a un lado esa carga semántica de tristeza, el carácter parlante del nombre, conviene realizar un breve repaso por la aparición de Tristán en la literatura medieval peninsular y su funcionalidad, tanto en prosa como en verso.

\section{TRISTÁN EN LA LITERATURA MEDIEVAL PENINSULAR}

Las alusiones a Tristán, el personaje, abundan en la lírica catalana y la gallegoportuguesa, así como en los textos castellanos aunque de forma algo más tardía ${ }^{3}$. Fue Guerau de Cabrera quien escribió la composición que contiene la primera alusión peninsular a Tristán (junto a Iseo), entre II59 y II65 ó II94, dentro de una lista de los conocimientos que se esperaban de un juglar. Mientras, en la lírica gallego-portuguesa su primera mención documentada aparece en una cantiga de amor de Alfonso X recogida en el Cancioneiro da Biblioteca Nacional en la que el poeta compara sus sufrimientos amorosos con los de Paris y Tristán, ciñéndose al tópico caballeresco ${ }^{4}$. Posteriormente, en el ámbito castellano, sus apariciones se multiplicaron en cancioneros como el Cancionero de Baena, el Cancionero de Román, el Cancionero de Martínez de Burgos, el Cancionero de Palacio o el Cancionero general; en romances, como el de Gerineldo, "Nunca fuere caballero", "Tres hijuelos había el rey" o "Ferido está don Tristán"; o en obras como el Libro de Buen Amor y el Tirant lo Blancs.

En el Cancionero de Baena, como ha señalado Cuesta Torre (1997), aparece en composiciones de Migir, Villasandino, Imperial o Ferrús, entre otros. A pesar

I Por el contrario, en los libros de caballerías encontramos personajes cuya impositio nominis responde a su fortuna, como Fortuna, la hija de Niquea y Amadís de Grecia de la Tercera Parte de Florisel de Niquea de Feliciano de Silva ("Y con esto la niña fue baptizada y puesto nombre Fortuna por el tiempo de su nascimiento, donde criándose para algún consuelo de la soledad de su madre y crecentamiento de su dolor las dexaremos hasta su tiempo", Silva, I999, cap. 55, p. 64), o Fortunián, hijo de la misma Fortuna, cuyo nombre se ha formado por hereditatio nominis.

2 También Isaÿe le Triste, supuesto hijo de Tristán e Iseo en un roman artúrico anónimo de principios del siglo XV escrito en picardo, recuerda en el nombre a su madre y en el sobrenombre a su padre y a la consabida tristeza (Borràs, 1999).

3 Las primeras alusiones se encuentran en la zona catalano-occitana, como han estudiado Lejeune (1959), Pirot (1972) o Cingolani (1992-1993).

4 Estas alusiones artúricas en la lírica galaico-portuguesa han sido analizadas por Sharrer (I988), Alvar (1993), y Cuesta Torre (1997).

5 Para un estudio detallado a este respecto debe consultarse el trabajo de Cuesta Torre (1997). 
de que Tristán y Merlín son los dos personajes artúricos de mayor presencia en la poesía de cancionero, aparecen otros como Lanzarote, Artús, Balán, Galaz, Ginebra, Iseo, José de Arimatea, Mares o Palomades (Cuesta Torre, I999a, pp. 77-78), los mismos que suelen comparecer ya sea en forma de cita o con cierta entidad en los libros de caballerías peninsulares, como ocurre con Balán en el Amadís de Gaula.

La figura de Tristán normalmente va unida a la de Iseo, pues ambos forman parte del paradigma de los amantes clásicos junto a Paris y Helena, Dido y Eneas o Píramo y Tisbe 6 . Esta nómina de estructuras binarias aumenta con los héroes y caballeros de la materia artúrica pero también caballeresca, como ocurre con Amadís y Oriana, que suelen acompañar a estas parejas en las composiciones cancioneriles. Sin embargo, en numerosas ocasiones, Tristán comparece en solitario o junto a otros caballeros y héroes masculinos en alusión a una de sus dos facetas, la caballeresca o la amorosa.

Así, Tristán se muestra en dos contextos bien diferentes: I) exaltando sus condiciones caballerescas junto a otros héroes de la talla de Lanzarote, Arturo, Galaz, Hércules o Amadís, o 2) como paradigma de los amantes junto a Iseo (en este caso normalmente junto a los mencionados Dido y Eneas, Píramo y Tisbe, etc.).

En lo referente a su exaltación caballeresca, podemos citar los mencionados ejemplos del Cancionero de Baena en las composiciones de Migir ("Eneas e Apolo, Amadís aprés / Tristán e Galaz, Lançarote del Lago”, Dutton- González Cuenca, 1993, comp. 38, p. 60), Ferrús ("Rey Artur e don Galaz, / don Lançarote e Tristán”, comp. 305, 1993, p. 54I), o Baena ("Yo leí del capitán / e grant duque de Bullón / de Narçiso e de Jasón, / d’Ércoles e de Roldán, / Carlosmanos e Florestán, / de Amadís e Lançarote, / Baldovín e Camelote, / de Galaz e de Tristán", Dutton- González Cuenca, 1993, comp. + 586, p. 745). También se retrata de igual manera en el desfile de personajes, seguidos por sus damas, que podemos leer en una composición anónima del Cancionero de Pero Guillén: "En éstos la corte del Rey Talamón / llegó faborable con gran policía, / Tristán, Lanzarote, quien bien parecía / trance qualquier librar por su mano, / viene Amadís Galás el muy llano / y todos los otros de los doce pares, / Roldán y Gayferos, los muy singulares, / con muchos amantes que claro no plano" (Cátedra, 1989, p. 338).

Sin embargo, su aparición no se circunscribe a la poesía de cancionero sino que su virtuosismo se plasma en otros textos de tal relevancia como el Arcipreste de Talavera o Corbacho de Alfonso Martínez de Toledo (I438) ("al animoso Godofré de Bullón; a Tristán de Leonís e Lançarote del Lago; a Lançalao, rrey de Nápoles", Martínez de Toledo, 1981, p. 285), o el Libro de las veynte cartas e quistiones (ca. I449) de Fernando de la Torre ("E qué es de la fortaleza de Sant-

6 Más concretamente, Tristán e Iseo forman también parte de los amores imposibles o desdichados, como también fueran los de Píramo y Tisbe recogidos en las Metamorfosis ovidianas. 
són, e Hércules el Fuerte, y de la gentileza de Paris y Jassón y de su vellocino dorado, e qué de la fermosura de Absalón o Narçiso, qué de la firmeza e lealtade de Tristán, Amadís y Riscardo", Díez Garretas, 1983, p. 132) en un ubi sunt conectado ya a su faceta amorosa. Sea como fuere, las secuencias son similares. Como puede observarse, predominan una vez más las estructuras bimembres, y Tristán va acompańado mayoritariamente de Lanzarote, su compańero y paralelo en la transmisión textual artúrica en la Península mediante los ciclos de la Vulgata y de la Post-Vulgata.

En cuanto a su faceta amorosa, de nuevo encontramos a Tristán citado por los poetas de cancionero recogidos por Cuesta Torre (1997, 1999a) como Juan Dueñas en un dezir del Cancionero de Palacio ("Car sin brebage amorosso, / como ya fue don Tristán, / gentil senyora, sabrán / que vuestro gesto fermosso / me conquistó por tal vía", Álvarez Pellitero, 1993, comp. 326, p. 224) o Francisco Imperial en Cancionero de Baena ("Todos los amores que ovieron Archiles, / Paris e Troilos de las sus señoras, / Tristán, Lançarote de las muy gentiles / sus enamoradas e muy de valores", "e otrosí de Tristán que fenesçió por amores", Dutton-González Cuenca, 1993, comps. 226 y 249, pp. 26I y 305). En este caso, la estructura bimembre se diversifica y la aparición del caballero se glosa haciendo referencia a algún episodio artúrico o a alguna de sus características.

Por último, sirve también Tristán como figura de sobrepujamiento; así ocurre en el Libro de Buena Amor del Arcipreste de Hita ("ca nunca tan leal fue Blancaflor a Flores nin es agora Tristán con todos sus amores”, Ruiz, 1990, I703ab, p. 72I), refiriéndose a su faceta amorosa.

En definitiva, no queda duda de que en la mayor parte de la literatura medieval peninsular la figura de Tristán se hallaba en la cumbre del ennoblecimiento y la fama, como paradigma del caballero en armas y en amores. Sin embargo, también es cierto que comienza a introducirse, como veremos con La Celestina, ese punto degradatorio del personaje que, aun así, recurre a su nombre como destino, para explicar su aparición en los textos. Pero conviene antes acercarnos a los textos que le son propios, los derivados artúricos, con el fin de obtener el retrato más fidedigno posible del caballero.

3. TRISTÁN EN LOS DERIVADOS ARTÚRICOS: ¿UN HÉROE TRISTE O ALEGRE? DEL TRISTÁN DE LEONÍS (I5OI) AL AMADÍS DE GAULA (I508)

El lugar que le es propio a Tristán, y es clave para la comprensión de su funcionalidad, es el de las obras artúricas derivadas del Tristan en prose y los ciclos de 
la Vulgata y de la Post-Vulgata, como pueda ser el Cuento de Tristán de Leonis, el Baladro del Sabio Merlin o, fundamentalmente, el Tristán de Leonis $(T L)^{7}$.

$\mathrm{Su}$ presencia es moderada en el Baladro del Sabio Merlín. Se menciona en un total de catorce casos, mayoritariamente por medio de una estructura lexicalizada que actúa como una suerte de sobrenombre, "el buen cavallero" (aplicada también a otros personajes como Morlote) ${ }^{8}$. Este sintagma nominal destaca una de sus dos facetas definitorias, la bélica, "e fue amigo de Tristán el buen cavallero" (p. 90), o "luego lo conocieron en el cabalgar que aquel era el buen cavallero don Tristán de Leonís". En tales términos aparece mencionado también en la Historia de las bienandanzas e fortunas de Lope García de Salazar: "Este Faramón creyó al buen caballero Tristán de Leonís" y "Eledus de Leonís, que fue padre del buen caballero e fermoso Tristán de Leonís" (Marín Sánchez, I999, Libro IX, fol $158^{\mathrm{v}}$ y Libro XI, fol. I8I $\mathrm{I}^{\mathrm{r}}$.

Normalmente en $B S M$, el sintagma aparece yuxtapuesto al nombre, como prueban los siguientes ejemplos: "E sabed que todas aquellas dueñas e donzellas que en prisión metiera que nunca dende salía ninguna viva, fasta aquel tiempo que Tristán, el buen cavallero, que fue a Irlanda e libró las que ende estaban vivas" (p. I2I), "ni fue alçada fasta que llegó ý después Tristán, el buen cavallero, que la alçó" (p. 174), "E esta campana que veis no se moverá por cavallero que aquí venga, que es en tal manera encantada, que no se podrá mover fasta que Tristán, el buen cavallero, venga aquí, que me ha de sacar" (p. I76) ${ }^{\mathrm{IO}}$.

Esta construcción, "el buen caballero", es recurrente en los textos caballerescos. Así aparece en el Amadís de Gaula (I508), padre y fundador de todos los libros de caballerías que vendrían después, y texto en el que la huella del Tristan en prose, y especialmente del TL, es incuestionable. En el Amadis, dicho sintagma se aplica a personajes como Amadís, Dardán, Guilán el Cuidador o Enil (con un total de doce casos).

De otro lado, y en lo que a Tristán atañe, el caballero aparece mencionado en el Amadis en cuatro ocasiones, una de ellas para hacer mención directa al texto, el Tristán de Leonís; otras dos para aludir a dos muertes llevadas a cabo

7 No trazaremos ahora su ya conocida trayectoria editorial sino que remitimos a los trabajos de Cuesta Torre (I991, I993 [vd. especialmente esquema p. 82], I993b).

8 Todas las citas procedentes del Baladro del sabio Merlin se han extraído de la transcripción de Hernández, 1999. Desde ahora BSM.

9 Ya Merlín augura en el BSM su prometedor futuro cuando el caballero "aún trebeja con la teta de su ama e no ha aún dos años complidos": "así parescerá Tristán sobre todos los caballeros [...] Tristán será la flor de los caballeros en bondat e en toda caballería [...] a todos pasará en bondad e fermosura" (p. I76).

Io También se menciona en el $B S M$ su faceta amorosa en una ocasión bajo una construcción de nuevo lexicalizada: "Tristán, leal amador" (p. 98). 
por el caballero, la de Morlote de Irlanda, hermano de la reina de Irlanda, y la de Bravor; y otra para referir su muerte "por causa de la reina Iseo, que era la cosa del mundo que él más amava" (Rodríguez de Montalvo, 1988, I, p. 330). De nuevo, ambas facetas, la caballeresca y la amorosa unidas, como también ocurre con Amadís. En las palabras que dieron título al trabajo fundacional de Cacho Blecua (1979) dedicado a la obra del medinés, se trata de un heroísmo mítico-cortesano.

Sin embargo, conviene ahora detenernos en el Tristán de Leonis, no tanto en la mención del héroe, muy numerosa, pues se trata del protagonista de la historia, sino de su tratamiento, en concreto de esa tristeza que parece intrínseca al personaje unida a su trágico nacimiento y a sus desgraciados amores con la reina Iseo. Pero antes hay que señalar las tres versiones peninsulares más importantes.

- Tristán medieval: se conservan un total de cincuenta y nueve fragmentos en el MSS/22644 de la Biblioteca Nacional de España (Madrid) (Alvar y Lucía Megías, 1999). Provienen de las tapas de encuadernación del MSS/I29I5 de la misma biblioteca en donde aparecen varias obras de derecho canónico. Data de principios del siglo XV y presenta numerosas miniaturas. ${ }^{\text {II }}$

-El Cuento de Tristán de Leonis: manuscrito en castellano-aragonés, probablemente de comienzos del siglo XVI (c. I5OI), conservado en el manuscrito 6428 de la Biblioteca del Vaticano, carente de los primeros cinco folios y editado por Northup. La historia está inacabada, consta de ciento cincuenta capítulos, y se ha postulado la presencia de cinco copistas.

- Tristán de Leonís: publicado en I5OI, consta de ochenta y tres capítulos, como la edición de Sevilla de 1528. En él aparecen insertas dos estrofas compuestas por Alonso de Córdoba para el Grimalte y Gradissa de Juan de Flores, uno de los puntos clave que ha permitido establecer su relación con la ficción sentimental.

Tomando la presentación crítica de los fragmentos del Tristán medieval llevada a cabo por Alvar y Lucía Megías (1999), nos encontramos con un Tristán que combina la alegría y la tristeza. Son escasos los ejemplos, pero podemos aportar los siguientes casos:

\section{TRISTE}

"Tristán quedó en la corte; e estava triste" (CT, p. 84). Sentimiento provocado al sentirse "flaco" para acudir al torneo a combatir con el Caballero de las Dos Espadas (Palomedes).

II Existen además dos fragmentos castellanos: MSS/20262/19 y el MSS/2202I de la Biblioteca Nacional de España (Madrid), datables respectivamente en los siglos XIV y XV-XVI. El último incluye una carta de Iseo a Tristán y su respuesta. A la misma versión parecen pertenecer los dos fragmentos catalanes de Andorra y Cervera (Beltrán, 1996, p. 37). 
"començó a fazer [muy] grant llanto por las cava[llerías que] tenían a dexar" (CT, p. 132). Cuando sabe pronta su muerte y se lamenta por morir en la cama y no en combate como buen caballero ${ }^{12}$.

\section{ALEGRE}

"él fue muy alegre" ( $C T$, p. 85). Tras haber recibido de Iseo joya, caballo y armas para acudir al torneo contra el Caballero de las Dos Espadas (Palamedes).

"fue muy alegre" (CT, p. I06). Al saber cómo el rey Arturo ha mandado preparar un torneo por amor de Tristán y de la reina Iseo.

"[fu]e muy alegre" ( $C T$, p. II $)$. Cuando en una contienda con Lanzarote en la que ambos van encubiertos y desconocen su identidad, el caballero le comunica su nombre.

Obtenemos, pues, una imagen equilibrada del héroe que puede resultar engañosa por el escaso número de fragmentos conservados. Ahora bien, el acercamiento a las otras dos versiones proporciona datos diferentes. Así, en el Cuento de Tristán de Leonis (CTL), se ofrece la imagen de un caballero pensoso y muchas veces airado y sañoso. Al contrario de lo que sucede, como se verá, en el Tristán de Leonis, en el que prima una imagen más compensada del héroe, en el CTL Tristán se hunde mayoritariamente en la tristeza y en la melancolía:

"fue muy triste \& yrado" (CTL, fol. 3r). Una vez leída la carta de Balisén tras haberse dado muerte por su amor no correspondido ${ }^{13}$.

" $\mathrm{C}$ (a) $[\mathrm{o}]<\mathrm{m}>$ mo trista $<$ n $>$ ente $<$ n $>$ dio estas pala- / bras mucho fue irado contra / la corte \& muy sañudo $\mathrm{q}<\mathrm{ue}>$ no $<\mathrm{n}>/$ sabia $\mathrm{q}<\mathrm{ue}>$ fazer $\mathrm{q}<\mathrm{ue}>$ uos dire $\mathrm{q}<\mathrm{ue}>\mathrm{ta}<\mathrm{n}>/$ gra $<\mathrm{n}>\mathrm{t}$ malenconia fue $\mathrm{q}<\mathrm{ue}>$ tomo $/ \mathrm{q}<\mathrm{ue}>$ el est $[\wedge \mathrm{udo}][\wedge \mathrm{a}] \mathrm{ua}$ co $>\mathrm{m}>$ mo om $<$ n $>$ e fue $-/$ ra de seso $\&$ mal dezia a todos / los cauall $<$ er $>$ os dela corte" (CTL, fol. 29v). Cuando descubre que Palomades se ha llevado a Iseo.

"un poco sañoso \& sali- / ose dela floresta irado (...) echose a dormjr q<ue> estaua / (l) [b]ie<n $>$ malenconjoso" (CTL, fol. 45v). Al no encontrar caza.

"t $<$ ristan $>$ fue asi $\mathrm{t}<\mathrm{r}>$ iste $\&$ yrado / $\mathrm{q}<\mathrm{ue}>$ no $<$ n $>\operatorname{sabia}(-) \mathrm{q}<$ ue $>$ decir $\mathrm{co}<\mathrm{n}>\mathrm{la}$ / gra $<$ n $>$ t tristeza E ot $<$ r $>$ o'si con / el dolor dela ferida no $<$ n $>$ se pudo tener \& cayo at<ie>rra" (CTL, fol. $47 \mathrm{r}$ ) Llora de dolor cuando no encuentra a la reina en la casa

I2 Así se expresa en el propio texto: “[¡Ay, mi Dios!, y ¡cómo mue]ra sin batalla de cavallero!; ¡ay, cavalleros andantes!, ¡cómo só triste porque yo muero sin batalla de cavallero, porque yo muero en el lecho!" (p. 132). Para más información acerca de la muerte de Tristán, ver Roubaud (2000), Cuesta Torre (2010), Contreras Martín (2010) y Coduras Bruna (20II).

I3 Se ha respetado literalmente la transcripción realizada por Corfis (1985). Agradezco al profesor Juan Manuel Cacho Blecua (Universidad de Zaragoza) el que me proporcionase dicho texto. 
en que la había dejado; y también, posteriormente, al alejarse por mar de Iseo, "fue muy / $\mathrm{t}<\mathrm{r}>\mathrm{i}$ 'ste por $\mathrm{q}<\mathrm{ue}>$ asy dexala rreyna $\mathrm{y}$ - / seo" (CTL, fol. 5 or).

"fue $\mathrm{t}<$ ristan $>$ muy ayra- $/$ do $\&$ come $<$ n $>$ ço a pensar $(. .$.$) en <$ e $>$ ste pensa- $/$ mje $<$ n $>$ to estovo $\mathrm{t}<$ ristan $>$ aq $<$ ue $>$ lla no- / che \& muy triste por la / perdida $\mathrm{d}<\mathrm{e}>\mathrm{l}$ rrey en ma- $/ \mathrm{n}<\mathrm{er}>\mathrm{a} \mathrm{q}<\mathrm{ue}>$ en toda la noche no $<\mathrm{n}>/$ dormjo sino muy poco" (CTL, fol. 66r-v). Cuando Tristán es informado de que el rey Arturo se ha perdido en la floresta.

Por el contrario, solo se encuentra un caso en el que Tristán se muestra alegre al llegar al Puerto de la Pequeña Bretańa ("fue mucho aleg<r $>\mathrm{e}$ ", CTL, fol. 5or). Por tanto, a pesar de reír con sus amigos en alguna ocasión (véase, por ejemplo, fol. 39r), el caballero se define como un hombre melancólico y sañudo, con tendencia a la tristeza que lleva en su antropónimo.

Sin embargo, su imagen varía al analizar el Tristán de Leonis, texto en el que nos detendremos fundamentalmente. En el anónimo Tristán de Leonís (I5OI) aparece en un total de mil setecientas diecisiete veces, nada de extrańar tratándose del protagonista del texto. Si bien es cierto que el adjetivo "triste" se le asocia en la narración en múltiples ocasiones, se atestiguan diez (de un total de sesenta y un casos en los que muchas veces se asocia a Lanzarote), lo supera en número el adjetivo "alegre", que aparece ciento cuatro veces en el Tristán de Leonis, en catorce asociado a Tristán ${ }^{14}$.

\section{TRISTE}

"e Tristán quedó triste de aquello que oyó, e entonce le dobló el dolor" (TL, p. 83$).{ }^{15}$

"E Tristán prometiógelo bien e lealmente, e cierto fuera si no que a poco tiempo murió Galeote, por lo cual fue muy triste" (TL, p. 55 ).

"E Tristán fue d'esta aventura muy triste" (TL, p. 73).

“- ¡Señor Dios, todos tiempos seré yo triste por esta dueña!" (TL, p. 5I)

"Mas Tristán, que estaba en la tienda con su tío, fue triste, e ovo gran pesar de las palabras que la donzella le avía dicho" (TL, p. 39).

"—Señora —dixo Tristán—, si yo vos he fecho algún daño, yo soy triste por ello" (TL, p. 164).

"[poema] "al triste que es amador" (TL, p. 98)

"e las nuevas fueron por toda la tierra tanto que lo supo Tristán, e fue triste porque no tenía algún escudero fiel a quien encomendase a la reina Iseo” ( $T L$, p. I23).

I4 Registro el término "tristeza" cuatro veces, mientras que "alegría" cincuenta y nueve.

I5 Todos los ejemplos del Tristán de Leonis se han extraído de Cuesta Torre (1999b). A partir de aquí $T L$. 
“-¡Ay, cativo de mí! ¿Qué haré?, que ya se entra el caballero en el castillo con la Dueña, e no me podré esta noche combatir con él, porque soy muy triste, que no sé qué faga" ( $T L$, p. 40).

"Y Tristán, cuando lo supo, fue triste por no le aver muerto" (TL, p. 44).

ALEGRE

"-Yo soy alegre. Dezidnos vuestro nombre e dezirvos hemos los nuestros" (TL, p. I3I).

“yo os trayo nuevas de vuestro sobrino Tristán, que es sano e alegre en la corte del rey Oel de la Pequeña Bretaña” (TL, p. 9I).

"Tristán fue alegre" (TL, p. I28)

"Cuando Tristán supo esto, fue alegre porque los avían fallado [...] E Tristán fue alegre de aquello que dixo la reina” (TL, p. 67).

"que era muy alegre de su venida [de la de Sagramor]" (TL, p. 76).

"don Tristán, esto vio, fue muy alegre" (TL, p. 5I).

"E Tristán, cuando la vio, fue el más alegre ombre del mundo" (TL, p. 83).

"Cuando Tristán esto supo, fue alegre [...] Muy alegres se fueron Tristán" (TL, p. 26).

"alegres amos a dos" (TL, p. IO6).

"E Tristán se tovo por buen guarido, e fue alegre" (TL, p. 27).

"Tristán fue muy alegre por estas nuevas" (TL, p. 95).

"E cuando Tristán lo oyó, fue alegre" (TL, p. 54).

"Cuando Tristán oyó este pregón, fue muy alegre" (TL, p. I27).

"E Tristán, cuando los vio venir, fue alegre de su tornada" (TL, p. 46).

Se produce, pues, una tensión entre la dilatación y el encogimiento del héroe en términos de la época; mientras la tristeza oprime al afligido, la alegría lo expande y se manifiesta con señales externas de contento, tal y como aduce Santo Tomás: "la causa porque con más prontitud mate el alegría que la tristeza es porque la sangre y los espíritus salen afuera y desamparan el corazón, dilatándose más de los justo, y así desfallece; como opreso y ahogado con la tristeza se apaga; porque de la alegría es propio dilatar que, como nace de la consecución del deseo, se ensancha y abre el corazón para recibir la cosa amada" (Covarrubias, 2006, p. IOI). En el TL son mayoritarias las manifestaciones externas del pesar pues "llanto" (I7 veces) y "llorar" (30 veces) suman cuarenta y siete casos, mientras que el término "risa" no aparece y "reír" lo hace solamente en diecisiete casos.

En el primero de los casos, la tristeza, predomina le expresión "fue (muy) triste" en tercera persona, o "soy (muy) triste" en primera persona singular, situación en la que el propio caballero nos transmite sus sentimientos. Esta tristeza le sobreviene al escuchar ciertas noticias, al conocer la muerte de algún compañero 
como Galeote o por razones amorosas en ocasiones causadas por él ("Señora dixo Tristán-, si yo vos he hecho algún daño, yo soy triste por ello”, p. I64).

En el segundo de los casos, su alegría, se expresa mediante la fórmula "fue (muy) alegre". Esta se suscita por diversas nuevas y el regreso de algún compañero como Sagramor ${ }^{16}$.

De este modo, la balanza se inclina hacia la alegría en el TL. Sin embargo, si comparamos estas proporciones con otro texto como el Amadís de Gaula en el que su huella, como ya hemos apuntado, es notable, las cifras cambian. Mientras que el adjetivo "triste" aparece cincuenta y tres veces, el adjetivo alegre lo hace en ciento cuarenta y nueve (y "contento/a", sesenta y dos), de tal forma que el panorama cambia, ya que el signo positivo está mucho más presente en el Amadis de Gaula que en el TL, de poso más melancólico.

Así, quizá no haya que tomar a pies juntillas la aseveración de que Tristán es el personaje más desdichado ("No sé si existirá un personaje más desgraciado, en la Edad Media, que éste”, López Alcaraz, 200I-2002, p. I30), aunque sí considerar que su tristeza es consustancial a obra y personaje, pues su nombre, surgido de la tristeza materna, "convendrá a su ser y a su existencia: tristeza en su parto, tristeza en su vida, tristeza en su muerte" (Cirlot, 2005, p. II9).

Sin embargo, este sino trágico no impidió que su nombre proliferara en la sociedad medieval y todavía áurea. Prevaleció por encima de la tristeza y la desgracia, su lealtad, su firmeza, su virtud y fue, sin lugar a dudas, el nombre artúrico más impuesto en la Península en la Edad Media, muy por encima de Lanzarote e incluso de Arturo (Artús, Artur), el principal protagonista de la materia bretona.

\section{EL NOMBRE TRISTÁN EN LA SOCIEDAD MEDIEVAL Y ÁUREA}

Como en el resto de países europeos, de entre los antropónimos artúricos, Tristán fue el nombre procedente de la materia de Bretaña más frecuente entre la sociedad medieval española. A este solían seguirle Lanzarote y Arturo, como ha estudiado Pastoureau (2004). Sin embargo, este orden no parece reproducirse en la Península dado que la presencia de Arturo es llamativamente bien escasa.

Varios son los estudios consagrados a la recepción de la literatura artúrica y su antroponimia en la Península. Ya Menéndez Pelayo, a comienzos del siglo xx, había apuntado en sus Orígenes de la novela (1905) cómo era moda cortesana en Portugal, "el tomar por dechados a los paladines del rey Artús y hasta el adoptar sus nombres" (Menéndez Pelayo, I905: 176) ${ }^{17}$. Ahora bien, sin duda, quien más

I6 El término "contento/a" solo aparece cuatro veces en el TL.

I7 No faltan los nombres de Ginebra y Viviana, y hay, sobre todo, gran cosecha de Tristanes 
se ha ocupado del rastreo de antropónimos artúricos en la sociedad medieval es David Hook. En "Esbozo de un catálogo cumulativo de los nombres artúricos peninsulares anteriores a 1300" (1996), recoge una nómina de personas que, antes de I300, recibieron el nombre de personajes artúricos, como Arturo, Galván y Merlín, y trató de mostrar cómo estos antropónimos inspirados en la materia artúrica de la Europa occidental se introdujeron medio siglo antes de la datación de los primeros textos artúricos peninsulares conservados. Este artículo culmina una serie de trabajos y notas como "Domnus Artux: Arthurian Nomenclature in I3th-c. Burgos" (1990), The Earliest Arthurian Names in Spain and Portugal (199I) o "Further Early Arthurian Names from Spain" (1993a). Finalmente, en "Transilluminating Tristan" (1993b), Hook encuentra cincuenta y tres individuos llamados Tristán, además de otros veintiuno con ese patronímico en fuentes documentales del periodo de 1475 a I5I3, un empleo muy superior al de cualquier otro nombre de origen literario. Buena prueba de su popularidad es que fue el nombre elegido por Rojas para uno de los criados de Calisto en la Tragicomedia.

Por su parte, Avalle-Arce, en "Onomástica épico-caballeresca en la Vasconia medieval” (1977), registra ciertos nombres de procedencia épico-caballeresca que recibieron diversas personas en la Vasconia medieval documentados por Lope García de Salazar en sus Bienandanzas y fortunas, tales como Florestán, Galás, Oger, Perceval, Tristán e Iseo. Observando estos datos uno cae en la cuenta de que la antroponimia artúrica se mezcla con la amadisiana. Por último, Ayllón (2005-2006) nos informa acerca de una tendencia en la España bajomedieval de llamar a los esclavos o hijos ilegítimos con nombres relacionados con la novela artúrica y los libros de caballerías. Y Beceiro Pita (1993) avanza en la misma dirección y señala la preeminencia de Tristán, pero aporta otros datos acerca de la gran importancia que adquirieron los antropónimos del Amadis en la Península.

Por nuestra parte, una rápida consulta al Portal de Archivos Españoles (PARES) nos proporciona un resultado de más de un centenar de casos de personas que recibieron el nombre de Tristán entre 1300 y 1570 . La mayoría se registra en León, pero también en Andalucía, País Vasco, Valencia, Galicia, Extremadura, Aragón, Cantabria, Asturias, Navarra, La Rioja, Barcelona y los pasajeros a Indias. Estos datos, de por sí bastante significativos, han de completarse con otros repertorios que definan en mayor medida y de forma más realista la expansión del nombre. Así, por ejemplo, solamente en un fogaje aragonés de 1495 he podido registrar diecinueve tristanes.

y Lanzarotes: Tristán Teixeira, Tristán Fogaça, Tristán de Silva, Lanzarote Teixeira, Lanzarote de Mello, Lanzarote de Seixas, Lanzarote Fuas, sin que falte un Percival Machado y varios Arturos, de Brito, de Acuña, etc." (Menéndez Pelayo, 1905: 176). 
Como ha estudiado Pardo de Guevara y Valdés (2009), Tristán fue nombre de gran influjo en los linajes de la nobleza gallega, pero este no se circunscribía a la nobleza sino que se extendía a todas las capas sociales, y así, por ejemplo, un Tristán Dualde zapatero registrado en el zaragozano barrio de San Lorenzo en una venta (9 de diciembre de 1507, Archivo Histórico Nacional, Clero-SeculaRegular, car. 3585, n.I2). También entre los poetas de cancionero del siglo Xv se encuentran numerosos tristanes: Tristán de Estúniga, Tristán da Silva, Tristán Teixeira y Diego Tristán (Cuesta Torre, 1999a, p. 8I). Y serían innumerables los ejemplos si siguiéramos indagando.

Si sumamos todos los datos de nuestra consulta, obtenemos el siguiente mapa peninsular, que ha de ser tomado con las consiguientes salvedades, prin-

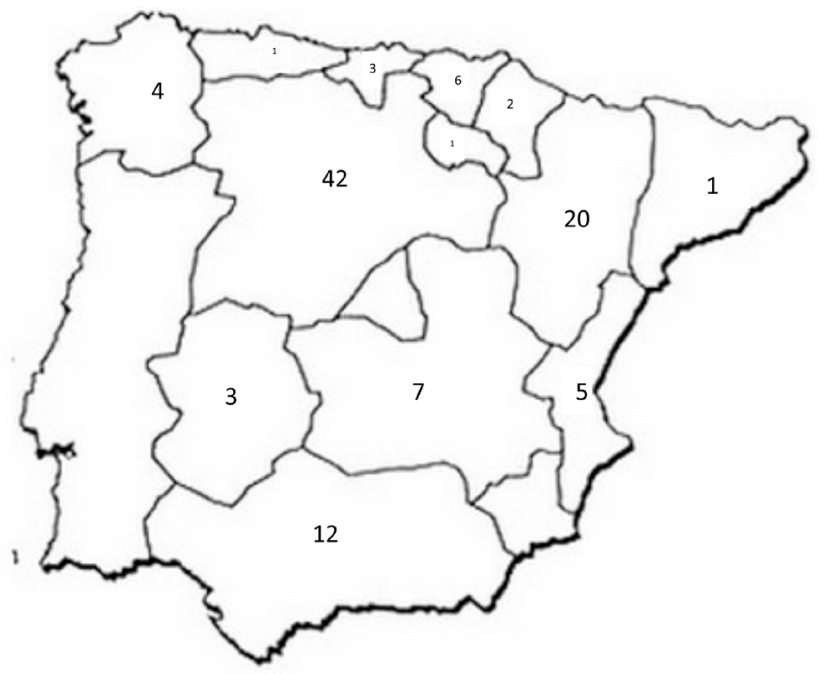

cipalmente como una muestra del reparto del antropónimo Tristán por toda la Península ${ }^{18}$.

Si bien es cierto que en muchas ocasiones Tristán ha pasado a ocupar el lugar de apellido, circunstancia que multiplica su aparición, la preeminencia de dicho antropónimo es evidente. Lo cual no quiere decir que Tristán fuera un nombre habitual en la Península, ya que en el Medievo y en el siglo xvi el repertorio onomástico masculino se restringía a Juan, Pedro, Alfonso (Alonso), Fernando, Diego, Domingo, Gonzalo y García, y el femenino a María, Juana,

I8 El mapa se ha confeccionado a partir de los resultados obtenidos en el Portal de Archivos Españoles (PARES) a la búsqueda sistemática del nombre Tristán, restringiendo la cronología de I300 a I570. A estos se han sumado los tristanes hallados en el fogaje de Aragón de 1495 (Serrano Montalvo, I995 y 1997). 
Isabel, Leonor, Teresa o Catalina. De hecho, casi la mitad de la población femenina, por influencia del culto mariano, se llamaba María, y una quinta parte de la masculina, Juan ${ }^{19}$.

En cuanto al locativo Leonís, que acompaña a Tristán en la mencionada obra homónima (Tristán de Leoniss), es el tercer nombre artúrico más frecuente en la Península, tras Galván, con un total de treinta y ocho casos localizados especialmente en Andalucía, con diecisiete casos, pero también en León, Castilla, La Rioja, Madrid, Extremadura, Valencia, y las Indias ${ }^{20}$.

Por último, la combinación perfecta sería la de Tristán de Leonís, y de esta también encuentro un registro en el mentado fogaje de Aragón de I495, en la calle Predicadores de Zaragoza (Serrano Montalvo, 1997, I, p. 85).

Si bien es cierto que el antropónimo iría perdiendo su carga semántica, el nombre de Tristán pudo motivar otro de signo opuesto, como prueba una curiosa anécdota. El cronista e historiógrafo Tristán de Silva bautizó a su primogénito Tristán de Silva, siguiendo la costumbre habitual de la herencia del nombre por parentesco. Tras la muerte de este, decidió llamar a su hijo Feliciano, por contraste con Tristán (Alonso Cortés, 1933, p. 383). Este Feliciano de Silva fue, curiosamente, el autor del Lisuarte de Grecia, el Amadis de Grecia, y las tres obras que conforman el Florisel de Niquea. Sin embargo, este caso no es único, sino que la tristeza asociada al nombre Tristán pasó a la sociedad contemporánea que tenía por costumbre llamar Tristán al hijo cuyo nacimiento conllevaba la muerte de la madre, siguiendo el argumento literario tristaniano.

\section{LA AMPLIACIÓN SEMÁNTICA DEL ANTROPÓNIMO TRISTÁN}

A la par que el nombre Tristán fue perdiendo su significado y sentido primigenios, se produjo una ampliación de las clases sociales de sus usuarios y de las connotaciones de su nombre parlante hasta llegar a dar nombre a personajes de baja estofa de la literatura áurea, normalmente criados cobardes y risibles. Sin duda, el caso más temprano y singular, es el de La Celestina de Fernando de Rojas, donde da nombre a uno de los criados de Calisto. La inclusión de un personaje de tal nombre tiene una función premonitoria pues, dar al mozo que acompaña

I9 Estos datos fueron obtenidos a lo largo de las investigaciones de mi tesis doctoral (Coduras Bruna, 2013). Para más información consultar el Apéndice I de la misma, dedicado a trazar un panorama de la antroponimia peninsular de finales del siglo XV y comienzos del XVI. En dicho apartado manejé los trabajos de Griswold y Tyler (196I), Barros García, Monsalvo Antón y Del Ser Quijano (1988), García Casar (1992), García Herrero (1992) y Pardo de Guevara y Valdés (2009), entre otros.

20 También Leonís ocupa muchas veces la posición de apellido, por lo que se ha desemantizado y su propagación es mayor por su carácter hereditario, como también sucederá con Galván. 
a Calisto en la noche que resultará ser su última visita al huerto de Melibea el nombre de Tristán, tiene una función premonitoria, de tal forma que el autor llega a presagiar la fatal muerte de los amantes (Reichenberger, 200I). Como afirma Cherchi, "Tristán es un hombre triste, que casi por metonimia vive la tristeza de su señor, le anuncia la muerte de los criados y luego anuncia la de Calisto" (Cherchi, 1997, p. 85).

Tras este, una estela de tristanes criados, muchas veces en la figura del gracioso, poblaron las comedias áureas. Así, el Tristán de la Dicha y desdicha del nombre de Calderón de la Barca, el Tristán de El perro del hortelano de Lope de Vega que ya encontramos huyendo en la primera escena, el ayo Tristán de la lopesca El anzuelo de Fenisa, el criado Tristán de La verdad sospechosa de Juan Ruiz de Alarcón, el Tristán de Lo que pasa en una venta de Quiñones de Benavente, o el criado Tristán de La doncella de labor de Juan Pérez Montalbán, entre otras comedias del siglo Xvir. En todas ellas, el aura caballeresca y heroica de Tristán de Leonís ha desaparecido y se ha tornado en su cruz, de lo más alto a lo más bajo, de lo serio a lo jocoso, del coraje a la cobardía.

\section{CONCLUSIONES}

Los ejemplos extraídos de la literatura y de la sociedad medieval y áurea apoyan la vinculación intrínseca de Tristán con la tristeza.

Tristán, paradigma del amante y del buen caballero, salió de las páginas artúricas para poblar, a manera de exemplum, la poesía de cancionero del siglo xv y otros textos de la relevancia de El Corbacho o el Libro de Buen Amor. Perteneciente al repertorio tan manido por los autores de la época de los leales y trágicos amadores junto a Iseo (a imagen de otras parejas como Píramo y Tisbe o Dido y Eneas) y de los grandes héroes (junto a Lanzarote, Héctor o Hércules), su figura rara vez fue objeto de chanza, salvo si nos atenemos a su aparición en La Celestina de Rojas, donde da nombre a uno de los criados de Calisto; personaje que motivaría toda una tradición del teatro áureo de tristanes como modelo del criado y del gracioso.

Salió también de los textos artúricos para dar nombre a multitud de personas de carne y hueso repartidas por toda la Península y, aunque perdida su carga semántica, se convirtió en el nombre propicio para nombrar a todos aquellos recién nacidos que, con su llegada al mundo, quitaron la vida a sus madres, siguiendo el argumento artúrico. 
No hay pues mejor ejemplo de la unión de ficción y realidad que la manifestada por la figura de Tristán, su fama, su virtud y notoriedad, y su arraigada tristeza.

\section{REFERENCIAS BIBLIOGRÁFICAS}

Alonso Cortés, N., 1933: "Feliciano de Silva", Boletin de la Real Academia Española, 20, pp. 382-404.

Alvar, C., I993: "Poesía gallego-portuguesa y Materia de Bretaña: algunas hipótesis", en O Cantar dos Trotadores. Actas do Congreso celebrado en Santiago de Compostela entre os días 26 e 29 de abril de 1993, Santiago de Compostela, pp. 373-385.

Alvar, C., y J. M. Lucía Megías, 1999: "Hacia el códice del Tristán de Leonís (cincuenta y nueve nuevos fragmentos manuscritos en la Biblioteca Nacional de Madrid)", Revista de Literatura Medieval, II, pp. 9-I35.

Álvarez Pellitero, A. Ma, (ed.), I993: Cancionero de Palacio, Salamanca.

Avalle-Arce, J. B., I977: "Onomástica épico-caballeresca en la Vasconia medieval”, en A. Bugliani (ed.), The two Hesperias: literary studies in honor of Joseph G. Fucilla on the occasion of his 8oth birthday, Madrid, pp. 4I-53.

Ayllón Gutiérrez, C., 2005-2006: "Lectura de caballerías y usos familiares en el siglo xv", Miscelánea Medieval Murciana, 29-30, pp. 39-56.

Barrios, A., J. Ma Monsalvo y G. Del Ser, I988: Documentación medieval del Archivo Municipal de Ciudad Rodrigo, Salamanca.

Beceiro Pita, I, 1993: "Modas estéticas y relaciones exteriores: la difusión de los mitos artúricos en la Corona de Castilla (siglo XIII - comienzos del siglo XvI)", España Medieval, I6, pp. I35-167. [reimpreso en Beceiro Pita, I., (2007): Libros, lectores y bibliotecas en la Espańa medieval, Murcia, pp. 245-285]

Beltrán Pepió, V., 1996: "Itinerario de los Tristanes", Voz y Letra 7/I, pp. I7-44.

Borràs Castanyer, L., 1999: "El hijo de Tristán, Isaÿe le Triste, o la locura como reescritura”, Revista de Literatura Medieval, II, pp. I65-178.

Cacho Blecua, J. M., 1979: Amadis: heroísmo mitico cortesano, Madrid.

Cátedra, P. M., 1989: La Historiografía en verso en la época de los Reyes Católicos. Juan Barba y su consolatoria de Castilla, Salamanca.

Cherchi, P., I997: “Onomástica celestinesca y la tragedia del saber inútil”, en J. L. Canet \& R. Beltrán (coord.), Cinco siglos de Celestina: aportaciones interpretativas, Valencia, pp. 77-90.

Cingolani, S., 1992-3: "The Sirventes-ensenhamen of Guerau de Cabrera: A Proposal For a New Interpretatio", Journal of Hispanic Research, I, pp. I9I-200. 
Cirlot, V., 2005: Figuras del destino. Mitos y simbolos de la Europa medieval, Madrid. Coduras Bruna, Ma , 2009: "Listas y libros de caballerías: una nómina de cruzados de las Sergas de Esplandián en el Lisuarte de Grecia", Tirant, I2, pp. 59-70.

Coduras Bruna, $\mathrm{M}^{\mathrm{a}}$, 20I3: La antroponimia en los libros de caballerías españoles: el ciclo amadisiano, Zaragoza.

Contreras Martín, A., 2010: "Muerte y entierro de Tristán en el Tristán de Leonis (Valladolid, I5OI)" en J. M. Fradejas, D. A. Dietrick, Ma J. Díez Garretas y D. Martín Sanz (coord.), Actas del XIII Congreso Internacional de la Asociación Hispánica de Literatura Medieval (Valladolid, I5-I9 de septiembre de 2009): in memoriam Alan Deyermond, Valladolid, I, pp. 554-562.

CORDE: Corpus Diacrónico del Español. Real Academia Española, <http:// corpus.rae.es/cordenet.html>. Última consulta 22/07/2013.

Corfis, I., 1985: Edition and Concordance of the Vatican Manuscript 6428 of the "Cuento de Tristán de Leonis", Madison (microficha, reproducido en ADMYTE 0, 1994).

Covarrubias, S. de, 2006: Tesoro de la lengua castellana o española, (ed. I. Arellano $\&$ R. Zafra), Madrid.

Cuesta Torre, Ma L. 1991: "Origen de la materia tristaniana: estado de la cuestión”, Estudios humanisticos. Filología, I3, pp. 185-298.

—_, 1993: "La transmisión textual de 'Don Tristán de Leonís", Revista de Literatura Medieval, 5, pp. 63-94.

—_ 1994: "Más sobre los orígenes y fuentes de la materia referida a Tristán", Estudios humanisticos. Filología, I6, pp. 27-48.

—_, I997: "Tristán en la poesía medieval peninsular", Revista de Literatura medieval, 9, pp. I2I-I44.

— I999a: "Personajes artúricos en la poesía de cancionero", en C. Parrilla \& J. I. Pérez Pascual (ed.), Estudios sobre poesía de cancionero, Noia, pp. 7I-II2.

—, (ed.), 1999b, Tristán de Leonis, Alcalá de Henares.

— 20I0: "Los funerales por Tristán: un episodio del Tristán castellano impreso en I5OI frente a sus paralelos franceses e italianos", en J. M. Fradejas, D. A. Dietrick, Ma J. Díez Garretas y D. Martín Sanz (coord.), Actas del XIII Congreso Internacional de la Asociación Hispánica de Literatura Medieval (Valladolid, I5-I9 de septiembre de 2009): in memoriam Alan Deyermond, Valladolid, I, pp. 599-615.

Díaz, J., I526: Lisuarte de Grecia. El octavo libro de Amadis, que trata de las estrañas aventuras y grandes proezas de su nieto Lisuarte, y de la muerte del inclito rey Amadis, Sevilla.

Díez Garretas, Ma J., I983: La obra literaria de Fernando de la Torre, Valladolid. 
Dutton, B. \& González Cuenca, J. (eds.), 1993: Cancionero de Juan Alfonso de Baena, Madrid.

Gallé Cejudo, R. J., 2004: "Elementos de la mitología clásica en las novelas de Tristán”, Cuadernos de Filología Clásica: Estudios latinos, 24/I, pp. 39-51.

García Casar, Ma F., 1992: Fontes iudaeorum regni castellae VI. El pasado judio de Ciudad Rodrigo, Salamanca.

García Herrero, Ma C., 1992: "Porque sepáis todos los nombres", en Un año en la historia de Aragón: 1492, Zaragoza, pp. 65-74.

Griswold, S. y R. W. Tyler, 196r: Los nombres de personajes en las comedias de Lope de Vega: estudio de onomatología, Madrid.

Hernández, Ma I. (ed), I999: Baladro del sabio Merlín. Transcripción y estudios, Gijón.

Hook, D., 1990: "Domnus Artux: Arthurian Nomenclature in $13^{\text {th }}$-c.Burgos", Romance Quarterly, 44, pp. I62-I64.

- 1991: The Earliest Arthurian Names in Spain and Portugal, St. Albans.

__, 1993a: "Further Early Arthurian Names from Spain", La Corónica, 21. 2, pp. 23-33.

_ on his $80^{\text {th }}$ Birthday, 17.2, pp. 53-84.

__ 1996: "Esbozo de un catálogo cumulativo de los nombres artúricos peninsulares anteriores a 1300", Atalaya, 7, pp.I35-I52.

Lejeune, R., 1959: “The Troubadours”, en R. S. Loomis (ed.), Arthurian Literature in the Middle Ages, Oxford, pp. 393-399.

López Alcaraz, J., 20OI-2002: "Tristán e Iseo: imágenes modernas de una leyenda medieval”, Estudios románicos, I3-I4, pp. I27-I54.

Lorenzo Grandín, P., 2005-2006: "Tristán en Portugal. Reescritura y alteración organizativa de las fuentes, Incipit, 25-26, pp. 357-380.

Marín Sánchez, A. Maa, 1999: Bienandanzas e fortunas de Lope García de Salazar, Valencia, <http://parnaseo.uv.es/Lemir/textos/bienandanzas/Menu.htm>.Última consulta 22/07/2013.

Martínez de Toledo, A., 198I: Arcipreste de Talavera o Corbacho (ed. M. Gerli), Madrid.

Menéndez Pelayo, M., 1905: Origenes de la novela. Vol. 2: Novela sentimental, bizantina, histórica y pastoril, Madrid.

PARES: Portal de Archivos Españoles. Ministerio de Educación, Cultura y Deportes, $<$ http://pares.mcu.es/>. Última consulta 22/07/2013.

Pardo de Guevara y Valdés, E., 2009: "Identidad y memoria genealógica. Una aportación al estudio de la antroponimia medieval gallega", Anuario de Estudios Medievales, 39/I, pp. 27-45. 
Pastoureau, M., 2004: "Jouer au roi Arthur. Anthroponymie littéraire et idéologie chevaleresque", en Una histoire symbolique du Moyen âge occidental, Paris, pp. 293-305.

Pirot, F., 1972, Recherches sur les connoisances littéraires des troubadours occcitains et catalans des XII' et XIII siècles: les 'sirventes-ensenhamens' de Guerau de cabrera, Guiraut de Calanson et Bertrand de Paris, Barcelona.

Plet-Nicolas, Fl., 2007: La création du monde. Les noms propres dans le roman de Tristan en prose, París.

Reichenberger, K. \& Th., 20oI: "Fernando de Rojas como comentarista político: acerca de la elección de nombres para los personajes" en P. Botta, F. Cantalapiedra, K. Reichenberger \& J. T. Snow (ed.), Tras los pasos de La Celestina, Kassel, pp. 225-250.

Rodríguez de Montalvo, G., I988: Amadís de Gaula (ed. J. M. Cacho Blecua), 2 vols, Madrid.

Roubaud, S., 2000: "Mort(s) et resurrection(s) d'Amadis", en Les Amadis en France au XVI siècle, París, pp. 9-19.

Ruiz, J., I990: Libro de Buen Amor (ed. J. Joset), Madrid.

Serrano Montalvo, A., 1995: La población de Aragón según el fogaje de I495. T. I, Sobrecullidas: Zaragoza, Alcañiz, Montalbán, Teruel, Albarracín, Daroca y Calatayud, Zaragoza.

- - I997: La población en Aragón según el fogaje de I495. T. II, Sobrecullidas: Fin de la de Calatayud, Tarazona, Huesca, Jaca, Ainsa, Barbastro y Ribagorza, Zaragoza.

Sharrer, H. L., I988: "La materia de Bretaña en la poesía gallego-portuguesa", en Actas del I Congreso de la Asociación Hispánica de Literatura medieval. Santiago de Compostela, 2 al 6 de diciembre de 1985, Barcelona, pp. 561-569.

Silva, F. de, 1999: Florisel de Niquea (Tercera parte) (ed. J. Martín Lalanda), Alcalá de Henares.

Tozer, A. J. A., 2004: “Tristán, Sosia and Centurio as Burlesque figures”, La corónica, 32/2, pp. I5I-I7I.

Yllera, A. (ed), I978: Tristán e Iseo, Madrid. 
